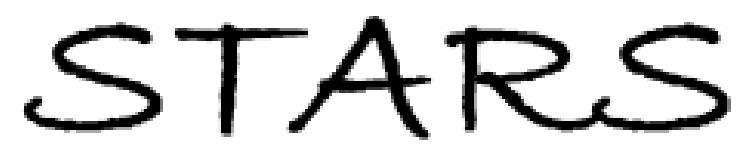

University of Central Florida

STARS

$1-1-2012$

\title{
Cooperative institutions for sustainable common pool resource management: Application to groundwater
}

Kaveh Madani

University of Central Florida

Ariel Dinar

Find similar works at: https://stars.library.ucf.edu/facultybib2010

University of Central Florida Libraries http://library.ucf.edu

This Article is brought to you for free and open access by the Faculty Bibliography at STARS. It has been accepted for inclusion in Faculty Bibliography 2010 s by an authorized administrator of STARS. For more information, please contact STARS@ucf.edu.

\section{Recommended Citation}

Madani, Kaveh and Dinar, Ariel, "Cooperative institutions for sustainable common pool resource management: Application to groundwater" (2012). Faculty Bibliography 2010s. 2983.

https://stars.library.ucf.edu/facultybib2010/2983

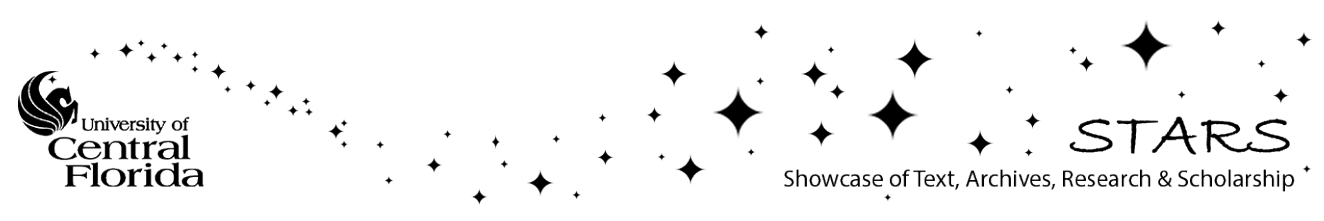




\title{
Cooperative institutions for sustainable common pool resource management: Application to groundwater
}

\author{
Kaveh Madani ${ }^{1}$ and Ariel Dinar ${ }^{2}$ \\ Received 25 April 2011; revised 27 July 2012; accepted 3 August 2012; published 27 September 2012.
}

[1] Beneficiaries of common pool resources (CPRs) may select available noncooperative and regulatory exogenous institutions for managing the resource, as well as cooperative management institutions. All these institutions may increase the long-term gains, prolong the life of the resource, and help to escape the tragedy of the commons trap. Cooperative game theory approaches can serve as the backbone of cooperative CPR management institutions. This paper formulates and applies several commonly used cooperative game theoretic solution concepts, namely, the core, Nash-Harsanyi, Shapley, and nucleolus. Through a numerical groundwater example, we show how CPR users can share the gains obtained from cooperation in a fair and efficient manner based on these cooperative solution concepts (management institutions). Although, based on their fairness rationales, various cooperative management institutions may suggest different allocations that are potentially acceptable to the users, these allocation solutions may not be stable as some users may find them unfair. This paper discusses how different methods, such as application of the plurality rule and power index, stability index, and propensity to disrupt concepts, can help identify the most stable and likely solutions for enforcing cooperation among the CPR beneficiaries. Furthermore, how the noncooperative managerial characteristics of the CPR users can affect the stability and acceptability of the different cooperative CPR management institutions is discussed, providing valuable policy insights for cooperative CPR management at community levels.

Citation: Madani, K., and A. Dinar (2012), Cooperative institutions for sustainable common pool resource management: Application to groundwater, Water Resour. Res., 48, W09553, doi:10.1029/2011WR010849.

\section{Introduction}

[2] It is not uncommon in practice to face situations in which beneficiaries are required to reduce uses of a scarce resource, e.g., fishery [Munro, 2009] and water during a drought [Zilberman et al., 1998], or reducing production levels of a public bad. e.g., greenhouse gas emissions reduction by countries [Cazorla and Toman, 2000], in order to increase their long-term benefits. The overarching commonality across such situations is the fact that the loss of immediate benefits and the gain of long-term benefits should be shared among the beneficiaries. In this paper, various cooperative institutions for management and sharing long-term benefits of common pool resources (CPRs) are reviewed and the effectiveness of each institution is explored.

[3] A CPR is defined as a resource system whose yield is subtractable and its characteristics make the exclusion of

\footnotetext{
${ }^{1}$ Department of Civil, Environmental, and Construction Engineering, University of Central Florida, Orlando, Florida, USA.

${ }^{2}$ Water Science and Policy Center, Department of Environmental Sciences, University of California, Riverside, California, USA.

Corresponding author: K. Madani, Department of Civil, Environmental, and Construction Engineering, University of Central Florida, Orlando, FL 32816, USA. (kavehmadani@gmail.com)

(C)2012. American Geophysical Union. All Rights Reserved. 0043-1397/12/2011WR010849
}

potential appropriators or limitation of the existing beneficiaries' rights nontrivial, but not necessarily impossible [Ostrom et al., 1994]. Not only do CPRs include the natural resources such as water, forests, pastures, oil, gas, fish, land, air, etc., but also the human-made resources that provide service and benefits (e.g., radio frequency spectra, reservoirs, irrigation infrastructure, wastewater treatment facilities, parks, roads, and other public infrastructures).

[4] Early works argued that in a joint usage of CPRs, parties are always driven by immutable logic of more withdrawal from (or less investment in) the CPR than what is optimal to sustain the system [Gardner et al., 1990]. Scholars with such a belief expected all CPR users to show noncooperative and competitive behaviors that make the tragedy of the commons [Gordon, 1954; Hardin, 1968] inevitable. The argument was that within a CPR dilemma, parties always base their actions on individual rationality (as opposed to rational group choices), which negatively affect all users eventually [Ostrom, 2010]. Within this school of thought, noncooperative game theory (the prisoner's dilemma game and the well-known Nash noncooperative stability definition (solution concept) [Nash, 1951]) provided a reasonable framework for illustrating the individualistic behavior of the parties to a CPR and exploring the resulting tragic outcomes [Madani, 2010]. To overcome the tragedy of the commons and avoid the inferior outcomes, two basic solutions have been suggested based on the complete rational decision maker paradigm: external regulations of extraction and 
appropriation of ownership rights [Castillo and Saysel, 2005].

[5] Ostrom [1990] challenged Hardin's pessimistic tragedy of the commons hypothesis, suggesting the possibility of existence of cooperative optimal outcomes for CPR problems, based on extensive field studies, real-world evidence, and lab experiments. Ostrom argued that the tragic outcomes are not necessarily inevitable for CPR problems, as CPR users do not always follow Nash strategies [Fehr and Fischbacher, 2002; Ostrom et al., 1994], which are merely based on individual rationality [Ostrom, 1998]. Finding the results of simple one-shot Nash solution-based CPR models and CPR games with finite repetitions solved by backward induction unreliable, Ostrom [1998] recognized the need for expanding the range of rational choice models to be used as a foundation for studying social dilemmas and collective actions. In her view, most previous models had failed to capture the reality of a decision-making process, which might be affected by different factors such as communication, trust, learning, and norms. As discussed by others [Madani and Hipel, 2011; Selbirak, 1994] the Nash noncooperative solution concept reflects the behavior of a risk-averse myopic player and fails to predict the accurate outcomes of real conflict situations, due to restricted assumptions underlying models of players' rationality. Thus, to improve the reliability of noncooperative CPR models, different modifications to the conventional noncooperative game theory analyses have been suggested, including: developing structures other than prisoner's dilemma for illustrating noncooperative CPR games [Gardner et al., 1990; Madani, 2010; Sandler, 1992; Taylor, 1987], introducing uncertainties or incomplete information in the game [Ostrom, 1998], studying CPR games as infinite repeated games in which players take mixed strategies [Ostrom et al., 1994]; defining CPR problems in a dynamic game context [Negri, 1989]; and analyzing games using noncooperative solution concepts (stability definitions) other than the Nash solution concept, which better reflect the decision makers' characteristics and behavior during the decision-making process [Madani and Lund, 2011; Madani and Hipel, 2011]. The results of the improved game models are consistent with the findings of Ostrom [1990] and Ostrom et al. [1994], which were based on both real cases and lab experiments. The results suggest that besides external solutions and appropriating exploitation rights to avoid tragic outcomes, the CPR users have the potential of escaping the resource depletion trap [Castillo and Saysel, 2005] through developing cooperative institutions and collective actions that can enforce sustainable exploitation and development of the resource.

[6] Madani and Dinar [2012] classified the available institutions for managing CPRs into three categories, namely the noncooperative, exogenous regulatory, and cooperative institutions. Under the noncooperative institutions, beneficiaries may either adopt myopic ignorant plans in which the long-term effects of exploitation plans and the externalities are ignored, or develop plans that are not myopic and/or ignorant. Madani and Dinar [2012] show that noncooperative institutions do not necessary result in tragic outcomes. Rather, sustainable CPRs may be achieved even under these institutions. Exogenous institutions include interventions by regulators (e.g., exploitation regulation, ownership rights assignment, and enforcement of different CPR governing rules) to overcome overexploitation of the resources and achieve sustainable CPRs [Madani and Dinar, 2011]. Under cooperative institutions, beneficiaries can base actions on group rationality and develop exploitation plans that increase the long-term gains for all users and provide them with sustainable benefits. Due to complexity of CPR problems and variability of their conditions, selection of an optimal management institution category (out of the three mentioned categories) that provides maximum benefits and enforces sustainability is nearly impossible [Madani and Dinar, 2012]. Instead, the optimum CPR management institution category should be selected considering the specific conditions of the problem. For instance, even though cooperative institutions may generally provide the highest benefits to the users, the complexity of the arrangements [Faysse, 2005] (e.g., transaction costs) may discourage parties from applying them in a given CPR problem, making these institutions inferior to the other two sets of institutions in that problem. Therefore, no specific CPR management institution has a strict dominance to other ones and depending on conditions of a CPR problem and the optimal CPR management institutions category can vary between CPR problems with different characteristics. Nevertheless, an in-depth study of all classes of CPR management institutions is essential to enable adoption of the most appropriate type of institution, given the conditions of the problem. Our previous works provide comprehensive studies of noncooperative CPR management institutions [Madani and Dinar, 2012] as well as exogenous CPR management institutions [Madani and Dinar, 2011]. Thus, this paper focuses on the third category of CPR management institutions, cooperative institutions, to clarify how they can provide a framework for achieving sustainable CPRs.

[7] In fact, cooperative CPR management institutions provide acceptable solutions, by not only prolonging the CPR's lifetime through sustainable and efficient exploitation, but also by satisfying the beneficiaries' equity concerns. CPRs can remain sustainable or may be brought back to a sustainable stage through contributions of stakeholders. It is possible to estimate the total required contribution of all parties to keep the CPR at a sustainable level. However, developing a fair and efficient scheme for allocating the achieved benefits among the parties is challenging, as often the CPR benefits are not equally distributed among the users.

[8] Cooperative game theory provides an appropriate framework for determining how CPR users can fairly and efficiently benefit from the CPR. However, most researchers have mainly focused on application of noncooperative game theory in CPR management studies [Faysse, 2005] and the applications of cooperative game theory concepts to CPR problems are limited. Dinar et al. [1986] used cooperative game theory solutions to design an efficient regional cooperation over reuse of municipal effluent for irrigation in a coastal plain region of Israel. Okada and Mikami [1992] apply cooperative game theory concepts to a hypothetical example in the U.S. and Canada to design effective and equitable methods to mitigate the acid rain problems. Using a water resource project in Southern California as a sample CPR Lejano and Davos [1999] discuss how cooperative game theory solution concepts for engendering and sustaining the necessary cooperation among the CPR beneficiaries. Lindroos and Kaitala [2000] apply 
cooperative game theory concepts to a fishery problem in Europe to explore the possibility of cooperation between the fishing nations. Petrosjan and Zaccour [2003] use cooperative game theory concepts to design a mechanism for cooperation among countries to reduce pollution or emissions. Zara et al. [2006], Parrachino et al. [2006], and Madani [2010] provide extensive reviews of applications of cooperative game theory concepts to natural, environmental, and water resource problems.

[9] While previous cooperative game theory applications in the CPR management context underline the value of cooperative game theory in designing fair and efficient mechanisms for allocating the benefits of CPRs, most of these studies ignore the stability and acceptability of the suggested cooperative mechanisms. Furthermore, to our best knowledge the effects of the noncooperative characteristics of the players on stability and acceptability of the cooperative solutions have not been explored in existing work.

[10] In this paper, we suggest several cooperative game theoretic solution methods to be used as cooperative CPR management institutions for estimation of the fair shares of the beneficiaries when CPR is exploited in a sustainable cooperative fashion. As is the case with many efficient policy interventions, they are not acceptable to all stakeholders, leading to derail of the policy. This study pays attention to such discrepancy and suggests different methods for evaluating the stability and acceptability of cooperative CPR management institutions. The major contribution, of the paper is in exploring the effects of noncooperative management behaviors of the CPR users on stability and acceptability of cooperative CPR management institutions. Knowledge of such effects can provide valuable insights to policy making for CPR management. The cooperative solution methods suggested in this study are appropriate for problems in which parties are willing to improve their foresight level and consider the long-term benefits of cooperation as long-term CPR planning and management requires reliable information about the future.

[11] In section 2, various cooperative CPR management institutions are reviewed and formulated. In section 3, a groundwater exploitation problem is introduced and modeled. In section 4 , the problem is solved through a social planning approach and the core of the problem is calculated. Cooperative management institutions are applied to the groundwater exploitation problem in section 5 , and the results are compared and discussed. In section 6 , different methods for evaluating the acceptability of the proposed solutions are introduced, and the stability of the solutions are examined. The paper concludes in section 7, with policy implications for sustainable management of CPRs in cooperative frameworks.

\section{Cooperative CPR Management Institutions}

[12] A CPR exploitation problem has been defined by Madani and Dinar [2012] as a pair $(Q, R)$ where $Q$ represents the vector of beneficiaries' actual exploitations and $R$ is the total available (remaining) amount of CPR to be exploited such that for beneficiaries $i=1,2, \ldots, n: e=$ $\left(Q_{1}, Q_{2}, \ldots, Q_{n}\right) \geq 0$ and $0 \leq \sum_{i=1}^{n} Q_{i} \leq R$. In this problem the beneficiaries' actual utility is defined as an $n$-tuple $u=$ $\left(u_{1}\left(Q_{1}\right), u_{2}\left(Q_{2}\right), \ldots, u_{n}\left(Q_{n}\right)\right)$ where $u_{i}\left(Q_{i}\right)$ is the utility of
CPR beneficiary $i$ from $Q_{i}$. Beneficiaries' expected utility is defined as an $n$-tuple $E u=\left(E u_{1}\left(e Q_{1}\right), E u_{2}\left(e Q_{2}\right), \ldots\right.$, $\left.E u_{n}\left(e Q_{n}\right)\right)$ where $e Q_{i}$ is beneficiary $i$ 's expected amount of exploitation from $R$ and $E u_{i}\left(e Q_{i}\right)$ is the expected utility of beneficiary $i$ from $e Q_{i}$, such that $\sum_{i=1}^{n} e Q_{i}$ is greater or smaller than $R$ and $Q_{i} \leq e Q_{i}$, and $u_{i}\left(Q_{i}\right) \leq E u_{i}\left(e Q_{i}\right)$ due to the exploitation externalities which lower the availability of the resource to the beneficiaries.

[13] An important characteristic of cooperative CPR management is the perfect information on the part of each beneficiary about the decisions and plans of other beneficiaries. In cooperative environments, CPR users may benefit from adoption of various cooperative game theoretic solutions, which result in higher gains for all beneficiaries $\left(u_{i}^{*} \geq u_{i}\right.$, where $u_{i}^{*}$ and $u_{i}$ are the utility of CPR beneficiary $i$ under cooperation and under the status quo, respectively). When additional benefit is achievable through cooperation, the main challenge is to fairly and efficiently allocate it among the cooperating parties. Such a challenge can be addressed through allocating the gains from cooperation using cooperative game theory concepts. An appropriate allocation under cooperation should satisfy the following constraints :

$$
\begin{aligned}
& u_{i}^{*} \geq u_{i} \quad \forall i \in N \\
& \text { (individual rationality condition) } \\
& \sum_{i \in s} u_{i}^{*} \geq \nu(s) \quad \forall s \in S, S \subseteq N
\end{aligned}
$$

(group rationality condition)

$$
\sum_{i \in N} u_{i}^{*}=\nu(N)
$$

(efficiency condition)

where for $N=\{1,2, \ldots, n\}, s$ is a feasible coalition (group of collaborating beneficiaries) in the game, such that $\{i\}$ ( $i$ $=1,2, \ldots, n)$ are the noncooperative coalitions with single beneficiaries and $N$ is the grand coalition which includes all beneficiaries; $S$ is the set of all feasible coalitions (all possible groups of beneficiaries) in the game; $\nu(s)$ is the value of coalition $s$ or the total obtainable benefits by the members of coalition $s$; and $\nu(N)$ is the value of the grand coalition.

[14] Each of the above equations reflects one important condition, which should be satisfied by the final cooperative allocation solution. Equation (1) enforces the individual rationality condition, requiring an allocation under cooperation to each beneficiary to be greater than what can be gained individually under no cooperation. Equation (2) fulfills the group rationality condition, requiring the sum of cooperative allocations to any group of beneficiaries to be greater that the total obtainable benefits under any coalition that includes the same beneficiaries. Equation (3) enforces the joint efficiency condition, requiring that the total obtainable benefits under the grand coalition to be fully allocated to the members of that coalition. The system of equations (1) to (3) establishes what is known as the core of the cooperative game [Gillies, 1959], a set of game allocation gains that is 
not dominated by any other allocation set. The core of a cooperative CPR management problem provides valuable insights by suggesting the range of acceptable solutions for each CPR beneficiary. The core includes an infinite number of cooperative solutions and provides a bound for the maximum benefit allocation that each beneficiary may request under cooperation. Satisfying the core conditions (equations (1) to (3)) for a cooperative (allocation) solution is a necessary condition for its acceptability by the players. Therefore, solutions not included in the core are also not acceptable and not stable [Shapley, 1971]. Nevertheless, being included in the core does not guarantee stability for a solution, as some users may find it unfair. Therefore, different methods are suggested to find the most stable and likely cooperative outcomes.

[15] The theoretical and empirical literature on cooperative game theory has introduced several solution concepts, including the widely used core, Nash-Harsanyi, Shapley, and nucleolus (which will be discussed and referenced later), and solution concepts, such as the kernel [Davis and Maschler, 1965], which is similar to the nucleolus but more cumbersome to apply in empirical setting; the generalized Shapley value [Loehman and Whinston, 1976], which refers only to coalitions that are practically possible rather than assigning equal probability to all possible coalitions from a combinatorial point of view in the Shapley value; the $\tau$ value [Tijs, 1981], which is the marginal contribution of a player to the grand coalition; and many others [see Parrachino et al., 2006]. We elected to calculate the core and apply the Nash-Harsanyi, Shapley, and nucleolus solutions mainly because they provide a unique solution that is in the core when it does exist and also for a practical matter: that these have been the most used solution concepts in natural resource allocation problems analyzed in the literature.

[16] Below, we formulate cooperative CPR management institutions, based on these three cooperative game theory concepts that provide solutions that are in the core and are potentially acceptable by the beneficiaries if the core is not empty.

\subsection{Nash-Harsanyi Institution}

[17] When obtaining extra benefits is possible through cooperation, CPR beneficiaries can apply the Nash-Harsanyi cooperative solution [Harsanyi, 1959, 1963], an extension of Nash bargaining solution for a two-player bargaining game [Nash, 1953]. To find the Pareto-optimal benefit allocation, use the following mathematical model:

$$
\Omega=\max \prod_{i=1}^{n}\left(u_{i}^{*}-u_{i}\right)
$$

subject to the core conditions (equations (1) to (3)), where $u_{i}^{*}-u_{i}$ is the gain of beneficiary $i$ from cooperation and $\sum_{i=1}^{n}\left(u_{i}^{*}-u_{i}\right)$ is the total benefits obtained through cooperation by the group of players. The Nash-Harsanyi institution provides a unique allocation solution that is included in the core (if it is not empty) by maximizing the product of the grand coalition members' obtained benefits from cooperation. Example applications of the Nash-Harsanyi bargaining solution in the water resources context include those of Dinar and Howitt [1997], Dinar [2001], and Madani [2011].

\subsection{Shapley Institution}

[18] Allocation based on the Shapley solution [Shapley, 1953 ] is another method for fair and efficient sharing of the obtained benefits under cooperation. Under this institution, allocations are determined based on the weighted average of the beneficiaries' contributions to all possible coalitions and sequences [Shapley, 1953], based on

$$
u_{i}^{*}=\sum_{\substack{S \subseteq N \\ i \in S}} \frac{(n-|s|) !(|s|-1) !}{n !}(\nu(s)-\nu(s-\{i\}))
$$

where for $\forall i \in N:|s|$ is the number of members of coalition $s$, and $n$ is the total number of beneficiaries in the allocation game. The Shapley solution is a unique solution that is in the core of convex games. Example applications of the Shapley concept in the water resources literature include those of Young et al. [1982], Dinar et al. [1992], Lejano and Davos [1995], Loehman [1995], and Dinar and Howitt [1997].

\subsection{Nucleolus Institution}

[19] The CPR beneficiaries can allocate the obtained benefits through cooperation based on the nucleolus solution [Schmeidler, 1969], which minimizes the worst inequity or dissatisfaction of the most dissatisfied coalition. The nucleolus of the benefit allocation game can be determined by finding $\varepsilon$ through the following optimization model:

$$
\max \varepsilon
$$

subject to

$$
\varepsilon \leq \sum_{i \in s} u_{i}^{*}-\nu(s) \quad \forall s \in S, S \subseteq N
$$

\section{Equation 3}

where $\varepsilon$ is the maximum tax imposed on all coalitions to keep them in the core. Solving the above mathematical model provides a fair and efficient allocation of benefits to the CPR, based on the nucleolus fairness principle [Schmeidler, 1969]. The nucleolus allocation is a single solution that is always in the core, if the core is nonempty. Example applications of the nucleolus solution in water resources management include those of Suzuki and Nakayama [1976], Kilgour et al. [1988], Lejano and Davos [1995], Loehman [1995], and Dinar and Howitt [1997].

[20] We explain how the suggested cooperative management institutions can be applied in practice to CPR management problems by presenting a groundwater problem in section 3 .

\section{Groundwater Exploitation Problem}

[21] Constituting 98\% of total liquid freshwater of the earth, providing $50 \%$ of potable water supplies, satisfying $40 \%$ of the demand of self-supplied industry, and supplying $20 \%$ of water use in irrigation [World Water Assessment Programme, 2003], make groundwater one of the most precious natural CPRs. The current rate of global groundwater withdrawals, about $750-800 \mathrm{~km}^{3} \mathrm{yr}^{-1}$ [Shah et al., 2000] or about a quarter of total global water withdrawals [Shah et al., 2004], which is in excess of natural groundwater 
recharge rate, has depleted groundwater resources. This has resulted in declining water tables, decreasing yields of wells, increasing pumping costs, competitive deepening of wells, land subsidence, loss of wetlands and flowing springs and rivers, salt water intrusion and other salinity problems, water quality degradation, and damaging aquatic ecosystems [Konikow and Kendy, 2005; Villholth, 2006]. Such negative effects are common in major regions of North Africa, the Middle East, South and central Asia, North China, North America, and Australia [Konikow and Kendy, 2005]. While the value of this resource and the dramatic economic benefits are known, the complexity in regulating and monitoring groundwater withdrawals have made sustainable management of this resource very challenging, making groundwater one of the most studied CPRs in the literature [Blomquist, 1992; Burke et al., 1999; Chebaane et al., 2004; Gardner et al., 1997; Gisser, 1980; Koundouri, 2004; Loaiciga, 2004; Provencher and Burt, 1993; Ross and MartinezSantos, 2009; Wegerich, 2006; Worthington et al., 1985]. The groundwater exploitation problem introduced by Madani and Dinar [2012] is presented briefly for application of cooperative CPR management institutions and a comparison of the obtained results under the cooperative management institutions with those obtained under the noncooperative and exogenous groundwater management institutions by Madani and Dinar [2011, 2012]. The groundwater exploitation problem is mathematically formulated as (more details about the model are given by Madani and Dinar [2012]):

$$
\begin{gathered}
C_{P, h}=\left(u s_{h}+v+d_{h-1}\right) Q_{h} \\
C_{h}=C_{P, h}+C_{\text {Tech }, h}+C_{\text {Other }, x, h} \\
C_{\text {Other }, x, h}=i_{x} l_{x, h}^{2}+j_{x} l_{x, h}+k_{x} \\
Y_{x, h}=\left(p_{x} l_{x, h}^{2}+q_{x} l_{x, h}\right) Q_{h} \\
R_{h}=\sum_{x} z_{x, h} \cdot Y_{x, h} \\
P_{h}=R_{h}-C_{h} \\
Z=\int_{0}^{H} P_{h} \cdot e^{-\beta h} d h
\end{gathered}
$$

where $C_{P, h}$ is the groundwater pumping cost at a given well at time step $h$ (for $h=1,2, \ldots, H$ ); $Q_{h}$ is the total discharge of the well at $h ; s_{h}$ is the groundwater drawdown at $h ; \mathrm{d}_{h-1}$ is the well water depth at the end of previous time step; $u$ and $v$ are cost parameters; $C_{\text {Tech }}$ is a one-time initial investment for irrigation technologies, represented by the time step equivalent $\operatorname{cost}\left(C_{T e c h, h}\right)$, e.g., annualized equivalent cost; $C_{\text {Other }, x, h}$ is the cost of seeds, fertilizer, planting, harvesting, etc. with regard to crop $x$ at during $h ; C_{h}$ is the total cost at $h ; l_{x, h}$ is the area under irrigation for growing crop $x$ during $h ; i_{x}, j_{x}$, and $k_{x}$ are cost parameters which depend on the crop type $(x) ; Y_{x, h}$ is the total yield of crop $x$ in $h ; p_{x}$ and $q_{x}$ are yield parameters which depend on the crop type $(x) ; R_{h}$ is the revenue gained through selling crops at the end of the growing season $h ; z_{x}$ is the price per weight unit of the crop $x$ in $h ; \beta$ is time step-dependent discount rate; $P_{h}$ is farmer's profit in $h ; Z$ is the total present value of farmer's profit; and $H$ is the length of the planning horizon.

[22] The groundwater drawdown in a single well with discharge of $Q_{h}$ during time step $h$ with a length $t_{h}$ (e.g., hour, week, month, and year) at distance $\lambda$ from the center of a well can be approximated, using equation (15) [Loaiciga, 2004]. Equation (15) varies by $\lambda$ and given $\lambda$, aquifer transmissivity ( $T$ ), and storativity, coefficients $a$ and $b$ can be estimated by regression of this equation against the predicted drawdown through the Theis equation for groundwater drawdown [Theis, 1935]:

$$
s_{h}=\frac{Q_{h}}{4 \pi T}\left(a \ln t_{h}+b\right) \quad \forall \lambda
$$

[23] When multiple $(n)$ wells are present, equation (15) fails to capture the mutual effects of extracted groundwater from the neighboring wells (externalities). In that case the actual drawdown at a $\mathrm{g}$ well $i$ can be estimated using equation (16) [Loaiciga, 2004]. This equation also varies by $\lambda_{i j}$ and coefficients $a_{i i}, b_{i i}, a_{i j}$, and $b_{i j}$ depend on the relative locations of other wells $(j=1,2, \ldots, n)$ with respect to well $i$.

$$
s_{i, h}=\frac{Q_{i, h}}{4 \pi T}\left(a_{i i} \ln t_{h}+b_{i i}\right)+\sum_{\substack{j=1 \\ j \neq i}}^{n} \frac{Q_{j, h}}{4 \pi T}\left(a_{i j} \ln t_{h}+b_{i j}\right) \quad \forall \lambda_{i j}
$$

[24] In estimating the drawdown, using equation (15) or (16), the net well discharges should be used which can be calculated using the following equation:

$$
Q_{i, h, N e t}=Q_{i, h}-\left(Q_{i, h, r}+\theta_{i} Q_{i, h}+\sum_{\substack{j=1 \\ j \neq i}}^{n} \omega_{i, j} Q_{j, h}\right)+Q e_{i, h}
$$

where $Q_{i}$ is the pumped discharge of well $i ; Q_{i, r}$ is the natural recharge of well $i$ that includes the general natural recharge of the aquifer (same recharge over the entire aquifer) as well as the local recharge (spatially variable); $\theta_{i}$ is the ratio of return flow from water use on farm $i$ to well $i$; $\omega_{i, j}$ is the ratio of return flow from water use on a farm $j$ to well $i$; and $Q e_{i}$ is the evaporative losses of well $i$.

[25] Madani and Dinar [2012] developed a numerical example to use the presented model under noncooperative CPR management institutions. The same numerical example was used by Madani and Dinar [2011] to examine the performance of regulatory exogenous CPR management institution. Here, we also use the same numerical example as a benchmark for comparing the performance of different cooperative institutions for managing CPRs. The problem includes three farmers, located on neighboring farms with different areas, with lot $\mathrm{A}$ being the largest and lot $\mathrm{C}$ being the smallest. Each farmer operates one well $(i=A, B, C)$, tapping into the same infinite aquifer. The wells have different initial water depths (or pumping costs) due to the 
Table 1. Values of Farmer-Dependent Parameters ${ }^{\mathrm{a}}$

\begin{tabular}{lccccccccccccc}
\hline & \multicolumn{10}{c}{ Parameter } \\
\cline { 2 - 13 } & $l$ Farmer & $d_{0}(\mathrm{~m})$ & $a_{i A}$ & $a_{i B}$ & $a_{i C}$ & $b_{i A}$ & $b_{i B}$ & $b_{i C}$ & $Q_{r}\left(\mathrm{~m}^{3} \mathrm{yr}^{-1}\right)$ & $\Theta$ & $\omega_{i, A}$ & $\omega_{i, B}$ & $\omega_{i, C}$ \\
\hline $\mathrm{A}$ & 40 & 20 & 9.125 & 5.423 & 3.640 & 140 & 100 & 50 & 1000 & 0.08 & 0 & 0 \\
$\mathrm{~B}$ & 28 & 14 & 5.423 & 9.125 & 6.684 & 100 & 140 & 115 & 900 & 0.07 & 0.085 & 0 \\
$\mathrm{C}$ & 15 & 9 & 3.640 & 6.684 & 9.125 & 50 & 115 & 140 & 750 & 0.06 & 0.035 & 0.075 & 0 \\
\hline
\end{tabular}

${ }^{\mathrm{a}}$ Madani and Dinar [2012].

slope of the farms, with well A having the maximum water depth and well $\mathrm{C}$ having the minimum water depth. Each farmer can choose from two crop options. Tables 1, 2, and 3 , respectively, present the values of farmer-dependent, crop-dependent, and independent parameters of the numerical example.

[26] To underline the value of the introduced cooperative CPR management institutions, these institutions are applied next to the numerical example.

\section{The Social Planner Solution}

[27] Before estimating the fair and efficient shares of the gains to the beneficiaries under cooperative management of a CPR, there is a need to determine the total obtainable benefit from cooperative management of the CPR during the planning horizon. That can be done based on the social planner solution which maximizes the total benefit received by the beneficiaries from the CPR without a concern about how to distribute the obtained benefits among the beneficiaries. The social planner solution for the numerical groundwater example can be found based on the following mathematical model:

$$
\max \sum_{i=A, B, C} Z_{i}
$$

subject to equations (8)-(14), (16), (17), and

$$
d_{i, h}=s_{i, h}+d_{i, h-1}
$$

where $\mathrm{d}_{i, h}$ is the well water depth for well $i$ at the end of time step $h$ and $s_{i, h}$ is the groundwater drawdown in well $i$, calculated based on equation (16).

[28] The maximum obtainable benefit (the net present value of the benefits from the entire planning horizon) for the entire group of users, determined by the above optimization problem, needs to be allocated among the individual members of the group, based on the introduced cooperative game theory solution concepts. Cooperative game theory solutions are expected to meet the fairness and efficiency conditions (equations (1)-(3)). Based on the social planner model (equations (18), (8)-(14), and (16)-(19)), the shares of each beneficiary from the CPR during the 50 year planning horizon of the example, are found to be $Z_{A}=$ $\$ 4,394,518, Z_{B}=\$ 0$, and $Z_{C}=\$ 0$ (all optimization problems have been solved using the What is Best commercial optimization software of LINDO Systems Inc. in this study). The results under the social planner solution suggest that the maximum benefit for the three farmers $(\$ 4,394,518)$ is obtained when only farmer A farms on his land. In fact, the model suggests that farmers $\mathrm{B}$ and $\mathrm{C}$ do not farm and do not extract water from their wells, so the externalities' effects are minimized. Therefore, the water level in Well A is only affected by the amount of water exploitation from this well alone. Although farmer $\mathrm{A}$ is dealing with the highest vertical pumping depth (or the highest pumping costs), having the largest land and economies of scale allows him to offset the pumping costs and gain the highest possible benefit for the system.

[29] Under the transferrable utility assumption (side payments), the only challenge is to suggest how the three farmers can share the maximum obtainable benefits in a fair and efficient manner. To be fair and efficient, the suggested allocation of the joint benefits should be in the computed core. The boundaries of the core can be calculated based on equations (1)-(3). To do that, we apply the social planner solution to all possible coalitions (except for the case of full noncooperation). Table 4 presents the value of possible coalitions with at least two members. To calculate the value of coalitions with two members, based on the social planner solution, two social planner models were developed. One model includes the two farmers participating in the coalition and the other includes the one that is not cooperating. By doing this, it is explicitly assumed that only in cases which have two cooperating farmers and one noncooperating farmer, the latter develops his exploitation plan for the whole planning horizon at the beginning, based on equation (18) and using equation (15) instead of equation (16), even if in the noncooperative mode this player might act differently. By using equation (15) in developing his long-term exploitation plan the noncooperative farmer ends up ignoring the externalities caused by the exploitation plan that is developed cooperatively by the other two farmers. This type of planning matches the characteristics of the "variable ignorant nonmyopic management", [Madani and Dinar, 2012],

Table 2. Values of Crop-Dependent Parameters ${ }^{\mathrm{a}}$

\begin{tabular}{ccccccc}
\hline \multicolumn{7}{c}{ Parameter } \\
\cline { 2 - 7 } Crop & $q\left(\mathrm{t} \mathrm{m}^{-3} \mathrm{ha}^{-1} \mathrm{yr}^{-1}\right)$ & $z\left(\$ \mathrm{t}^{-1}\right)$ & $i\left(\$ \mathrm{ha}^{-2} \mathrm{yr}^{-1}\right)$ & $j\left(\$ \mathrm{ha}^{-1} \mathrm{yr}^{-1}\right)$ & $k\left(\$ \mathrm{yr}^{-1}\right)$ & $p\left(\mathrm{t} \mathrm{m}^{-3} \mathrm{ha}^{-2} \mathrm{yr}^{-1}\right)$ \\
\hline 1 & 0.0256 & 150 & $-9.8175 \times 10^{-3}$ & 892.5 & 2.769 & $-2.49 \times 10^{-10}$ \\
2 & 0.0280 & 134 & $-9.8485 \times 10^{-3}$ & 689.4 & 0.611 & $-7.51 \times 10^{-11}$ \\
\hline
\end{tabular}

${ }^{\mathrm{a}}$ Madani and Dinar [2012]. 
Table 3. Values of Independent Parameters ${ }^{\mathrm{a}}$

\begin{tabular}{cccccccccc}
\hline$A$ & $B$ & $t^{\mathrm{b}}$ & $T\left(\mathrm{~m}^{2} \mathrm{~d}^{-1}\right)$ & $u\left(\$ \mathrm{~m}^{-3} \mathrm{~m}^{-1}\right)$ & $V\left(\$ \mathrm{~m}^{-3}\right)$ & $\beta\left(\% \mathrm{yr}^{-1}\right)$ & $C_{\text {Tech }}(\$)$ & $Q e_{i}\left(\mathrm{~m}^{3} \mathrm{yr}^{-1}\right)$ & $H\left(\mathrm{years}^{2}\right)$ \\
\hline 9.125 & 140 & 365 & 6960 & 7.2 & 10 & 0.05 & 0 & 0 & 50 \\
\hline
\end{tabular}

${ }^{\mathrm{a}}$ Madani and Dinar [2012].

${ }^{\mathrm{b}}$ Note that $t$ should be set equal to 365 in equations (1) and (2) to calculate the drawdown over one time step $(h)$.

which may be used in the noncooperative mode by farmers who develop long-term exploitation plans in absence of information on plans of other players. Similarly, the two cooperating farmers have no information on the externalities, resulting from the exploitation plan of the noncooperating farmer, when developing their long-term cooperative plan, based on equation (18). In this case, the two collaborating farmers use equation (16) (and not equation (15)) as a constraint in their planning model. Once the values of decision variables of the two models have been determined through the two models (two-farmer and one-farmer models), the actual gains of the players can be estimated by simultaneous consideration of the planning variables of the two models. This will indeed allow capturing the externalities through equations (16) and (17), which estimate the actual drawdown in the wells of the cooperating and noncooperating farmers.

[30] It should be emphasized that here, we are explicitly assuming that there is a public choice mechanism leading to agreement over development of the exploitation management plan using the same method. The social planner solution for the grand coalition (three farmers as a group) is developed based on the characteristics of the variable ignorant nonmyopic management, the same principles are used to estimate the values in any case other than the full noncooperation case, in which all farmers act independently. In other words, it is assumed that once there are at least two parties who cooperate to develop their long-term exploitation plan based on the variable ignorant nonmyopic management institution, the other party will use the same institution as a response strategy, no matter how he behaves in the fully noncooperative case. Nevertheless, when no party is willing to cooperate (the case of coalitions with one member only), they are allowed to adopt different noncooperative management institutions. Perhaps future studies should consider the cases in which coalitions smaller than the grand coalition may adopt different management institutions for planning their exploitations. However, that can make the problem highly complex, requiring a high computational capacity. It is noteworthy that while the social planning method used by the grand coalition matches the variable ignorant nonmyopic management institution, the coalition members are not necessarily ignorant of externalities.

Table 4. The Values of Different Coalitional Settings Excluding One-Member Coalitions

\begin{tabular}{lcccc}
\hline & \multicolumn{3}{c}{$\begin{array}{c}\text { Gain Based on the Social } \\
\text { Planner Solution (\$) }\end{array}$} & \\
\cline { 2 - 3 } Coalition & Farmer A & Farmer B & Farmer C & $\begin{array}{c}\text { Total Coalition } \\
\text { Value (\$) }\end{array}$ \\
\hline$\{$ A, B $\}$ & $3,742,295$ & 21,014 & & $3,763,309$ \\
$\{$ A, C & $2,682,139$ & & 0 & $2,682,139$ \\
$\{B, C\}$ & & $1,459,786$ & 0 & $1,459,786$ \\
$\{$ A, B, C $\}$ & $4,394,518$ & 0 & 0 & $4,394,518$ \\
\hline
\end{tabular}

Indeed, since there is a member operating out of the grand coalition there is no need for the coalition members to worry about the externalities and variable ignorant nonmyopic management results in the highest level of benefits for the grand coalition. In this case, planning using the "smart ignorant nonmyopic management" institution which requires a continuous update of the management plan after each time step would yield the same result at a greater level of effort and cost.

[31] Since in case of full noncooperation (when all coalitions include one member only) noncooperating farmers may adopt different management institutions for developing their exploitation plans, coalitions with one member can have different values, based on the noncooperative management institution used by the only member of the coalition. The logic behind considering a range of possible managerial characteristics/attitudes in the noncooperative environment, i.e., noncooperative management institutions, for the same users who adopt a specific management institutions when acting together, i.e., the variable ignorant nonmyopic management, is that the behavioral characteristics of a user in a group are not necessarily the same when acting on his own. For example, two thieves who have had a long-term business relationship based on group rationality may prefer to make decisions based on self-rationality when experiencing a prisoner's dilemma situation. This is because parties change behaviors as a result of the breakdown of a group, associated with loss of trust, creation of a competitive environment, dominance of free ride, etc., even if before the group's breakdown their decisions have been based on group rationality. On the other hand, parties who compete for maximizing their benefits from a CPR with no consideration of the long-term feedback of their decisions on their benefits change attitudes and become more considerate of the externalities and long-term effects of their decisions when maximizing their joint longterm benefits. What makes studying a range of noncooperative management institutions necessary is that noncooperative parties can have different behavioral characteristics and adopt different choices of noncooperative management institutions. Similarly, in a prisoner's dilemma game decision makers may not be always free riders [Madani and Hipel, 2011]. Another important reason for considering the different noncooperative management institutions is that the different noncooperative behavioral characteristics of the farmers can have considerable effects on the stability of the possible cooperative management institutions, as will be proved numerically later in the paper.

[32] The values of one-member coalitions are given in Table 5, which shows how the choice of noncooperative management institutions, as described in Table 6, can affect the realized benefits of farmers over the planning period. Generally, noncooperative farmers can increase their benefits and prevent tragedy of the commons by replacing their short-term (myopic) and aggressive exploitation plans that fully ignore externalities (ignorant or egoistic behavior) 
Table 5. The Possible Values (\$) of Different One-Member Coalitions Under Different Noncooperative Management Institutions ${ }^{\mathrm{a}}$

\begin{tabular}{lcccccc}
\hline & \multicolumn{5}{c}{ Noncooperative Management Institution } \\
\cline { 2 - 7 } & $\begin{array}{c}\text { Ignorant Myopic } \\
\text { Management }\end{array}$ & $\begin{array}{c}\text { Smart Myopic } \\
\text { Management With } \\
\text { Drawdown Penalty }\end{array}$ & $\begin{array}{c}\text { Smart Myopic } \\
\text { Management With } \\
\text { Profit Penalty }\end{array}$ & $\begin{array}{c}\text { Fixed Ignorant } \\
\text { Nonmyopic } \\
\text { Management }\end{array}$ & $\begin{array}{c}\text { Variable Ignorant } \\
\text { Nonmyopic } \\
\text { Management }\end{array}$ & $\begin{array}{c}\text { Smart Nonmyopic } \\
\text { Management }\end{array}$ \\
\hline$\{$ A & $1,410,745$ & $1,607,507$ & $1,711,671$ & $2,199,330$ & $2,209,329$ & $2,410,089$ \\
$\{B\}$ & 99,216 & 344,681 & 214,975 & 790,681 & 744,047 & 918,662 \\
$\{$ C & $-106,141$ & $-14,466$ & $-8,180$ & 70,617 & 40,259 & 167,173 \\
Sum & $1,403,820$ & $1,937,722$ & 1918,466 & $3,060,627$ & $2,993,636$ & $3,495,924$ \\
\hline
\end{tabular}

${ }^{\mathrm{a}}$ Madani and Dinar [2012].

through (1) consideration of the externalities in their development plans (smart or altruistic behavior) and/or (2) development of long-term plans (nonmyopic behavior). Based on smart noncooperative institutions the effects of externalities are considered in developing the management plan through different heuristics such as self-imposed penalties (e.g., assuming that the actual drawdown will be higher than what is expected, or the obtained profit will be less than what is planned) or continuous revision of the exploitation plan over time based on the latest available information about the status of the CPR. Nonmyopic noncooperative institutions are based on maximizing the long-term benefits as opposed to the short-term benefits, as done in the myopic management institutions. The highest benefits are realized by the noncooperative farmers when the applied management institution is nonmyopic and smart. On the other hand, lower benefits are obtained when the exploitation plans lack both or one of the two characteristics. Such plans can even result in considerable losses (negative profit) for some farmers who start farming with profit expectation, but end up with costs higher than revenues due to the externalities, ignored in their management plans [Madani and Dinar, 2012]. Comparing the values in the last row of Table 5 with the social planner solution of the problem shows that depending on the noncooperative management institution used by the farmers, cooperation of three farmers can result in an extra benefit of $\$ 898,594$ to $\$ 2,990,698$, which should be allocated to the three farmers, based on the introduced cooperative management institutions.

[33] The values given in Tables 4 and 5 allow calculating the boundaries of the core, based on equations (1)-(3), in order to find the farmers' preference orders over the possible cooperative solutions. Using an example, the procedure for finding the boundaries of the core and calculating the extreme points of the core are illustrated in Appendix A. Finding the extreme points helps us find the minimum and maximum benefits that each player can expect from participating in the grand coalition. Figure 1 indicates the minimum and maximum expected benefits of the three farmers when they use various types of noncooperative management institutions in the status quo (under noncooperation). The obtained values indicate that as farmers become less myopic by replacing their short-term plans with long-term ones, and less ignorant by developing exploitation plans that consider the externalities, the solution space (core) becomes smaller. This can be explained by the fact that the incremental benefit of cooperation decreases as farmers get smarter and more considerate.

\section{Cooperative Groundwater Management Results}

[34] The results based on the social planner solution suggest that cooperative groundwater management institutions can provide the highest benefit to the farmers in comparison with noncooperative and exogenous groundwater management institutions. Results of Madani and Dinar [2012] indicate that within a noncooperative management framework where farmers may benefit from various noncooperative CPR management institution options (Table 6), farmers can increase their total gain up to $149 \%$ by replacing myopic ignorant exploitation plans with nonmyopic

Table 6. Noncooperative Groundwater Management Institutions

\begin{tabular}{|c|c|}
\hline Name & Description $^{\mathrm{a}}$ \\
\hline Ignorant myopic management & User develops a short-term plan with no consideration of externalities. \\
\hline $\begin{array}{l}\text { Smart myopic management with } \\
\text { drawdown penalty }\end{array}$ & $\begin{array}{l}\text { User develops a short-term plan and tries to consider the externalities based on his past experience regarding } \\
\text { groundwater drawdown. This user assumes that the actual drawdown will be } \mathrm{x} \text { units higher than the expected } \\
\text { drawdown, where } \mathrm{x} \text { is equal to the average difference between the expected and actual drawdown in previous } \\
\text { time steps. }\end{array}$ \\
\hline $\begin{array}{l}\text { Smart myopic management with } \\
\text { profit penalty }\end{array}$ & $\begin{array}{l}\text { User develops a short-term plan and tries to consider the externalities based on his past experience regarding } \\
\text { obtained profit. This user assumes that the actual profit will be y units higher than the expected profit, where } \\
\text { y is equal to the average difference between the expected and actual profit in previous time steps. }\end{array}$ \\
\hline $\begin{array}{l}\text { Fixed ignorant nonmyopic } \\
\text { management }\end{array}$ & $\begin{array}{l}\text { User develops a plan with fixed decision variables for a long term with no consideration of the externalities. } \\
\text { The operation variables of this user (e.g., groundwater withdrawal, area under cultivation, crop type, etc.) do } \\
\text { not change across time steps. }\end{array}$ \\
\hline $\begin{array}{l}\text { Variable ignorant nonmyopic } \\
\text { management }\end{array}$ & $\begin{array}{l}\text { User develops a plan with variable decision variables for a long term with no consideration of the externalities. } \\
\text { The operation variables of this user can vary across time steps. }\end{array}$ \\
\hline Smart nonmyopic management & $\begin{array}{l}\text { User develops a long-term plan with variable decision variables and tries to consider the externalities by } \\
\text { continuous revision of the long-term plan. }\end{array}$ \\
\hline
\end{tabular}

${ }^{\mathrm{a}}$ For comprehensive description of these institutions, readers are referred to Madani and Dinar [2012]. 
(a)

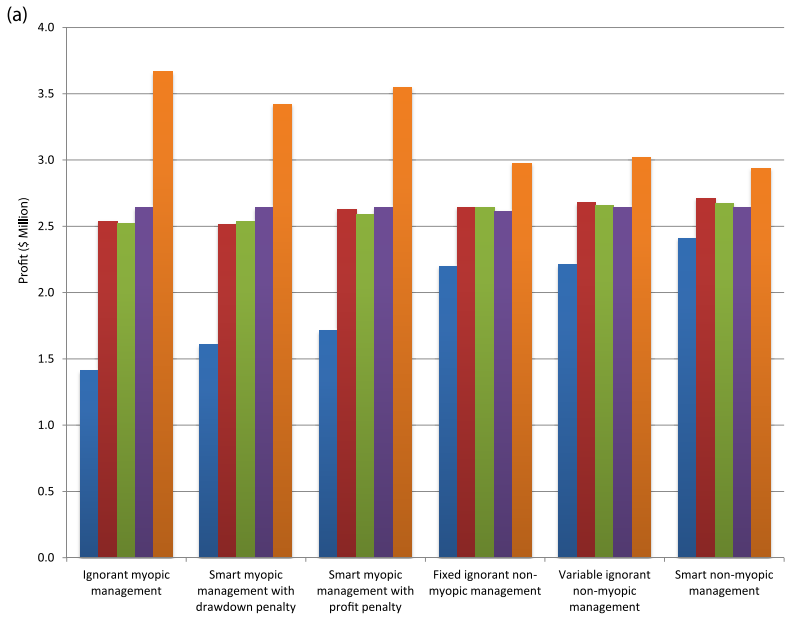

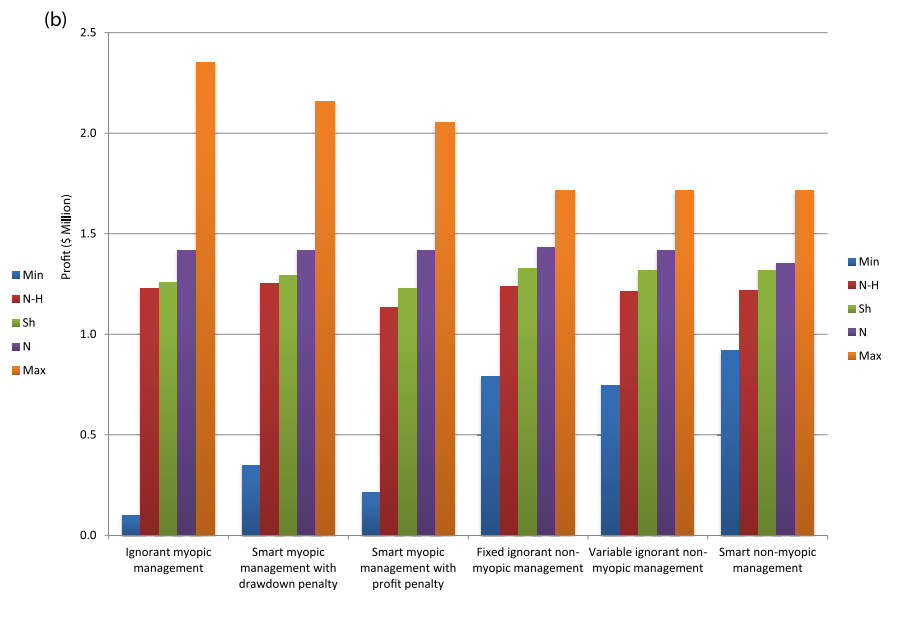

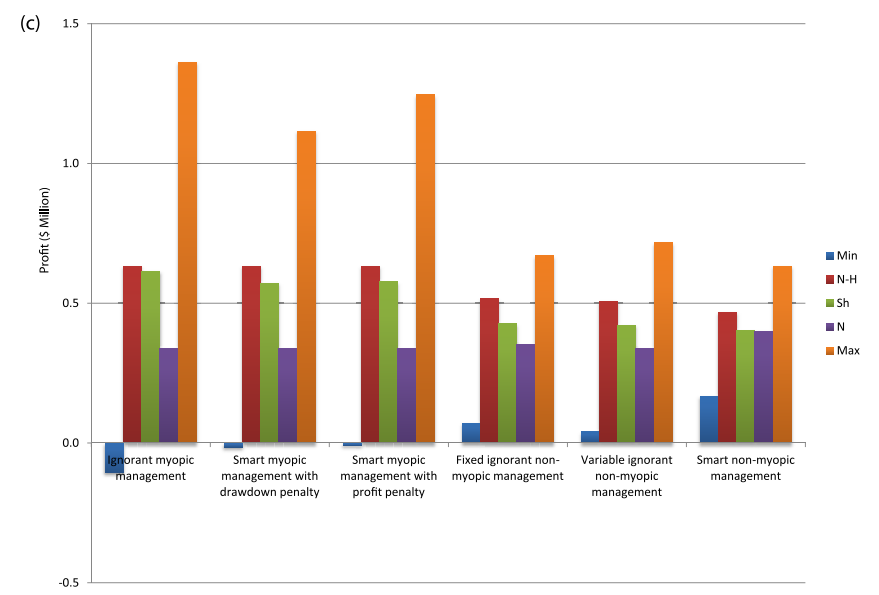

Figure 1. The minimum (Min) and maximum (Max) expected benefits of (a) farmer A, (b) farmer B, (c) farmer $\mathrm{C}$ using various types of noncooperative management institutions in the case of noncooperation (status quo) and the allocated benefits to the farmers based on various cooperative management institutions $(\mathrm{N}-\mathrm{H}=$ Nash-Harsanyi, $\mathrm{Sh}=$ Shapley, and $\mathrm{N}=$ nucleolus $)$.

smart exploitation plans. Madani and Dinar [2011] found that by interference of a regulator through some commonly used exogenous regulatory groundwater management institutions the total gain of the myopic ignorant farmers may rise by up to $138 \%$. This indicates that long-term planning and consideration of the externalities by the farmers may be more efficient than interference of the regulators through some commonly used exogenous regulatory management practices, suffering from imperfect information at the design stage and high transaction costs. Here, the results based on the social planner solution show that through cooperation the total gain of the noncooperating farmers may increase by $213 \%$. This suggests that cooperative management institutions are the most efficient institutions in increasing the gain to the CPR beneficiaries and prolonging the CPR's life in comparison with noncooperative and exogenous CPR management institutions. Nevertheless, the given number (213\%) may be too optimistic, as the transaction costs of establishing cooperative management institutions have not been considered here.

[35] Given the values of Tables 4 and 5, we can calculate the gain to each farmer, based on different cooperative allocation institutions introduced earlier. Figure 1 shows the allocated benefits to the three cooperating farmers, based on different cooperative institutions. The cooperative shares of the farmers vary, based on the noncooperative institution they choose in case of noncooperation (status quo). All cooperative solutions based on the three suggested institutions satisfy the core requirements (equations (A1) to (A7)). Therefore, they are in the core and are acceptable by the users. However, the level of acceptability and stability of the allocated benefits may vary among the users, as will be discussed in section 6 . Considering the computational limitation only cases in which all farmers apply the same management institution have been examined here (public choice mechanism as explained earlier).

[36] According to Figure 1, farmer C, the smallest farmer (poorest in terms of land resources), is the one who benefits the most from cooperation with respect to what he could gain noncooperatively. The opposite is true for farmer $\mathrm{A}$, the largest farmer (richest in terms of land resources). Generally, as users become less myopic by developing long-term plans and less ignorant by considering the externalities, their relative benefit from cooperation decreases. Therefore, the ignorant myopic farmers benefit the most and smart nonmyopic farmers benefit the least from cooperation with respect to the status quo. That may suggest that ignorant myopic farmers have higher desire to cooperate than farmers who plan long 
term and/or consider the externalities in the exploitation plans. Yet, in practice, the ignorant myopic farmers may be reluctant to cooperate, as they cannot perceive the long-term benefits. Therefore, enforcing cooperation may be more convenient when parties are considerate of the externalities and long-term benefits.

[37] Comparison of the results suggests that in most cases farmer $\mathrm{C}$ (the smallest farmer) gains less under the Shapley institution than under the Nash-Harsanyi institution. The opposite is true for farmer $\mathrm{B}$, who is not as large as farmer $\mathrm{A}$ and not as small as farmer $\mathrm{C}$. The reason for that result lies in the calculation of the Shapley and NashHarsanyi institutions. In the case of Nash-Harsanyi, each farmer gets an equal incremental gain based on its original benefit at the status quo; however, the Shapley institution allocates incremental gains to each farmer based on their average contribution to the coalition when they enter that coalition. In this case, when entering the coalition, farmer B has more contribution than farmer C. Thus, farmer B's coalitional gains are higher. Gains of farmer A do not differ significantly under the Nash-Harsanyi and Shapley institutions.

[38] When comparing the gain of the smallest farmer, farmer $\mathrm{C}$, under different cooperative management institutions, one can find that this farmer gains the least under the nucleolus institution. On the other hand, farmer B, with the middle wealth level, gains the most under this institution in comparison with what he gains under the other two institutions (the nucleolus calculation procedure suggests that it would take the lowest $\varepsilon$ to keep a coalition with $C$ in the core and a higher $\varepsilon$ to keep a coalition with $\mathrm{B}$ in the core). Gain of the largest farmer, farmer A, under the nucleolus institution does not have a significant difference with his gains under the other two institutions in most cases.

[39] The results under the three cooperative management institutions rely on an important assumption. Here, it is assumed that utility is transferrable and side payments are allowed. Therefore, in case of cooperation, it is suggested that only farmer A, with the lower production cost per unit, farms on his land and shares the benefits with the other two farmers. In this case, the three farmers can enjoy a lower depth to groundwater (a longer CPR life) due to minimization of the externalities caused by simultaneous pumping in all the wells. Nevertheless, the solution may be associated with some transaction costs. When utility is not transferrable and side payments are not allowed, the problem finds a different structure. While cooperation may still result in higher benefits and prolong the CPR's life, the maximum total benefits obtained will be lower than a case with side payments. In that case, farmers would cooperate by lowering their pumping rates to prolong the groundwater resource's life and keeping pumping costs lower than the benefits obtained from crop production. Therefore, all farmers will farm on their lands while they are enjoying lower groundwater depths; however, some transactions costs associated with monitoring and enforcement may be experienced. This case is not studied here. Nonetheless, the gains of the farmers under the cooperation can be calculated using the same concepts. For example, the farmers' gains from cooperation based on the Nash-Harsanyi institution can be calculated using the Nash-Harsanyi bargaining solution for linked games [Madani, 2011]. In that case, farmers see the game as interconnection of $\mathrm{H}$ (here $\mathrm{H}=50$ ) games linked to each other. Therefore, the "strategic loss" becomes possible and farmers are willing to strategically lose in some years (in some subgames) to increase their gain (win) in the overall interconnected game. By benefiting from strategic loss, the feasible solution space is expanded and parties can develop cooperative solutions that increase the gains to all parties.

\section{Acceptability and Stability of the Cooperative Institutions}

[40] To ensure that a cooperative solution works properly in practice, not only should it be in the core, but also it has to be stable. While being in the core is a necessary condition for acceptability of a cooperative solution by the beneficiaries, not all solutions contained in the core are acceptable. Some solutions that fulfill the core requirements are found unfair by some beneficiaries, making them unacceptable and unstable. When beneficiaries find a solution unfair, they may threaten to leave the grand coalition to form subcoalitions or to act on their own, due to their critical role in the coalition [Dinar and Howitt, 1997].

[41] When multiple cooperative solutions are available, one simple method to find which solution is superior to others is using the plurality rule finding which method is the most preferred option by the most number of users. The plurality rule is perhaps the most common method for finding the socially optimal solution. Other socially optimal rules (e.g., Condorcet choice, Borda scoring, median voting rule, majoritarian compromise, and Condorcet's practical method) can be used in similar situations when multiple users have a chance to select a best alternative. Fallback bargaining methods [Brams and Kilgour, 2001] can be also used to find the optimal alternative in these situations. See Sheikhmohammady and Madani [2008] for explanation and example applications of various social rules and fallback bargaining methods. Table 7 indicates how the various cooperative management institutions in the numerical example are ranked from 1 (worst option) to 3 (best option) by the farmers using the plurality rule. As indicated in Table 7, the ranking orders of the farmers over the possible alternatives vary, depending on the noncooperative management institution they will adopt in the status quo. The plurality rule selects the option considered best by the highest number of users as the socially optimal alternative. The last row of Table 7 indicates which cooperative management institution is selected, based on the plurality rule, depending on the users' behavioral characteristics in the noncooperative case. Results indicate that the Shapley institution is never selected. Therefore, this institution cannot provide stable solutions to enforce cooperation among the three farmers. Based on Table 7, the nucleolus institution is most preferred by the majority of the farmers when they are myopic. When they consider their long-term benefits under noncooperation, the Nash-Haryanvi institution is preferred by the majority. Since the selected alternative, based on the plurality rule, always complies with the best choice of farmer A, who has the highest level of power due to his highest wealth level, it is reasonable to expect the plurality rule's selected option to be stable in practice.

[42] The choice of cooperative institutions can vary based on the conditions of the problem. The Nash-Harsanyi cooperative institution may not be appropriate for all 
Table 7. Preference Orders of the Farmers Over the Cooperative Management Institutions Based on Their Noncooperative Characteristics $^{\mathrm{a}}$

\begin{tabular}{|c|c|c|c|c|c|c|c|}
\hline & & \multicolumn{6}{|c|}{ Noncooperative Management Institution } \\
\hline & $\begin{array}{l}\text { Cooperative } \\
\text { Management } \\
\text { Institution }\end{array}$ & $\begin{array}{c}\text { Ignorant } \\
\text { Myopic } \\
\text { Management }\end{array}$ & $\begin{array}{c}\text { Smart Myopic } \\
\text { Management } \\
\text { With Drawdown } \\
\text { Penalty }\end{array}$ & $\begin{array}{c}\text { Smart Myopic } \\
\text { Management } \\
\text { With Profit } \\
\text { Penalty }\end{array}$ & $\begin{array}{l}\text { Fixed Ignorant } \\
\text { Nonmyopic } \\
\text { Management }\end{array}$ & $\begin{array}{c}\text { Variable } \\
\text { Ignorant } \\
\text { Nonmyopic } \\
\text { Management }\end{array}$ & $\begin{array}{c}\text { Smart } \\
\text { Nonmyopic } \\
\text { Management }\end{array}$ \\
\hline \multirow[t]{3}{*}{ Farmer A } & Nash-Harsanyi & 2 & 1 & 2 & 3 & 3 & 3 \\
\hline & Shapley & 1 & 2 & 1 & 2 & 2 & 2 \\
\hline & Nucleolus & 3 & 3 & 3 & 1 & 1 & 1 \\
\hline \multirow[t]{3}{*}{ Farmer B } & Nash-Harsanyi & 1 & 1 & 1 & 1 & 1 & 1 \\
\hline & Shapley & 2 & 2 & 2 & 2 & 2 & 2 \\
\hline & Nucleolus & 3 & 3 & 3 & 3 & 3 & 3 \\
\hline \multirow[t]{3}{*}{ Farmer C } & Nash-Harsanyi & 3 & 3 & 3 & 3 & 3 & 3 \\
\hline & Shapley & 2 & 2 & 2 & 2 & 2 & 2 \\
\hline & Nucleolus & 1 & 1 & 1 & 1 & 1 & 1 \\
\hline \multicolumn{2}{|c|}{ Selected institution based on the plurality rule } & Nucleolus & Nucleolus & Nucleolus & Nash-Harsanyi & Nash-Harsanyi & Nash-Harsanyi \\
\hline
\end{tabular}

${ }^{a}$ Note that 3 and 1 indicate the most and least preferred options, respectively.

problems as it sometimes may provide unfair allocations, especially if there are big utility differences between the users (e.g., very rich and very poor beneficiaries) [Dinar and Howitt, 1997].

[43] While plurality rule is a simple method for determining the most stable cooperative solution, due to its qualitative nature, it fails to provide some useful quantitative information about the stability of the solutions available through application of other stability measurement methods. Propensity to disrupt player $i\left(P T D_{i}\right)$, the ratio of how much the other beneficiaries would lose if player $i$ leaves the grand coalition and refuses to cooperate to how much he would lose if he refuses to cooperate, has been suggested as an indicator of players' powers in a cooperative framework [Gately, 1974; Straffin and Heaney, 1981]:

$$
P T D_{i}=\frac{\sum_{j \neq i} u_{j}^{*}-\nu(N-i)}{u_{i}^{*}-\nu(i)}
$$

[44] The lower the ratio for a given player, the higher his enthusiasm for cooperating and staying in the grand coalition. The user who has a high enthusiasm for cooperation has a low power in the grand coalition. On the other hand, a player with a high propensity to disrupt has a high power in the grand coalition, using his high contribution to the grand coaltionas a basis for a credible threat to the other members of the grand coalition. This player threatens to leave the grand coalition to create subcoalitions or act on his own, asking for more benefits out of cooperation.

[45] Table 8 presents the calculated propensity to disrupt of the farmers for different cooperative solutions, which vary based on their choice of noncooperative management institution in status quo. The values in Table 8 suggest that the propensity to disrupt under a given cooperative management institution increases as they become less myopic and less ignorant. This is due to the fact that by long-term planning and consideration of the externalities farmers can increase their gains even without cooperation. That also underlines the value of information. Parties who are aware of the externalities' effects and are concerned about the CPR's conditions in the long run have more power when it comes to cooperation.

[46] The value of 0 propensity to disrupt for a myopic farmer $\mathrm{C}$ under the Nash-Harsanyi cooperative institution

Table 8. Propensity to Disrupt of the Farmers Under Different Cooperative Management Institutions Based on Their Choice of Management Institution in the Status Quo

\begin{tabular}{|c|c|c|c|c|c|c|}
\hline \multirow[b]{2}{*}{$\begin{array}{c}\text { Cooperative } \\
\text { Management } \\
\text { Institution }\end{array}$} & \multicolumn{6}{|c|}{ Noncooperative Management Institution } \\
\hline & $\begin{array}{c}\text { Ignorant Myopic } \\
\text { Management }\end{array}$ & $\begin{array}{c}\text { Smart Myopic } \\
\text { Management With } \\
\text { Drawdown Penalty }\end{array}$ & $\begin{array}{c}\text { Smart Myopic } \\
\text { Management } \\
\text { With Profit Penalty }\end{array}$ & $\begin{array}{l}\text { Fixed Ignorant } \\
\text { Nonmyopic } \\
\text { Management }\end{array}$ & $\begin{array}{c}\text { Variable } \\
\text { Ignorant } \\
\text { Nonmyopic } \\
\text { Management }\end{array}$ & $\begin{array}{c}\text { Smart } \\
\text { Nonmyopic } \\
\text { Managemen }\end{array}$ \\
\hline \multicolumn{7}{|l|}{ Nash-Harsanyi } \\
\hline Farmer A & 0.35 & 0.47 & 0.33 & 0.65 & 0.55 & 0.75 \\
\hline Farmer B & 0.43 & 0.51 & 0.63 & 1.07 & 1.07 & 1.65 \\
\hline Farmer C & 0.00 & 0.00 & 0.00 & 0.26 & 0.27 & 0.55 \\
\hline \multicolumn{7}{|l|}{ Shapley } \\
\hline Farmer A & 0.37 & 0.43 & 0.39 & 0.66 & 0.62 & 0.98 \\
\hline Farmer B & 0.39 & 0.45 & 0.48 & 0.72 & 0.70 & 0.99 \\
\hline Farmer C & 0.02 & 0.10 & 0.09 & 0.58 & 0.55 & 0.98 \\
\hline \multicolumn{7}{|l|}{ Nucleolus } \\
\hline Farmer A & 0.11 & 0.11 & 0.11 & 0.12 & 0.11 & 0.11 \\
\hline Farmer B & 0.21 & 0.21 & 0.21 & 0.20 & 0.21 & 0.27 \\
\hline Farmer C & 0.88 & 0.88 & 0.88 & 0.80 & 0.88 & 0.58 \\
\hline
\end{tabular}


(Table 8) suggests that this farmer has a very high enthusiasm to stay in the grand coalition as the other players will not lose without him. In such a situation, this farmer may be willing to bribe the other farmers by increasing their gains and asking for less benefit out of the joint cooperative gains. Although by doing this farmer $\mathrm{C}$ ends up with lower cooperative gains, he can create an incentive for the other players to stay in the grand coalition. Therefore, when the players act myopically in status quo, a cooperative solution close to what was suggested by the Nash-Harsanyi institution may be stable. However, given the high propensity to disrupt farmer B under this institution, it may be concluded that when farmers become nonmyopic the Nash-Harsanyi cooperative solution cannot be stable anymore. For myopic farmers, the Shapley institution seems a fair scheme for allocating gains with the lowest maximum propensity to disrupt. However, this institution cannot provide stable solutions for smart nonmyopic farmers, as was discussed earlier. Given that farmers A and B are wealthier and more valuable to the grand coalition than farmer $\mathrm{C}$, it is reasonable to conclude that cooperative solutions in which farmers $\mathrm{A}$ and $\mathrm{B}$ have lower propensity to disrupt are more stable. In that case, the nucleolus seems to be the best institution for allocating the cooperation benefits.

[47] Calculating the power index of player $i\left(\alpha_{i}\right)$ in the cooperative game is another method for evaluating the stability of the cooperative solution [Loehman et al., 1979; Shapley and Shubik, 1954]:

$$
\alpha_{i}=\frac{u_{i}^{*}-\nu(i)}{\sum_{j=1}^{n}\left(u_{j}^{*}-\nu(j)\right)}, \sum_{i=1}^{n} \alpha_{i}=1
$$

[48] Based on this concept, to determine if a solution is stable, the power index of each player is calculated based on the given cooperative solution. The higher the power index of a player is, the higher that player's enthusiasm is for cooperating and staying in the grand coalition. This method suggests that if the power is distributed more or less equally among the players, then the solution is more likely to be stable [Dinar and Howitt, 1997]. Looking at the coefficient of variations of power indices, known as stability index $(\bar{\alpha})$, one can find if the power distribution is equally distributed among the users. The lower the stability index, the more stable the cooperative solution.

[49] Table 9 shows the calculated power indices of the farmers and stability index of each cooperative solution for different cooperative solutions, which vary based on their choice of noncooperative management institution in status quo. Based on the results, Nash-Harsanyi cooperative institution seems to have the best performance in distributing the powers equally among the farmers of the numerical example. Although, the nucleolus institution fails to distribute the powers equally among the farmers, given the conditions of the problem, it may provide a stable solution as it gives higher powers to the wealthier (larger) farmers, so it allows them to remain in the coalition and influence the poorer (smaller) ones.

[50] Figure 2 indicates the stability index of each cooperative solution, which varies based on farmers' choice of noncooperative management institution in the status quo. Based on the results, Nash-Harsanyi institution shows the best performance (lower stability indices) for all status quo's noncooperative behavior types. The opposite is true for the nucleolus institution. The performance of the Shapley institution is almost insensitive to the noncooperative behaviors of the farmers in status quo. As the users become less myopic and smarter, stability index gets smaller under NashHarsanyi institution, indicating the possibility of developing stable solutions under this institution for farmers with better behaviors.

\section{Conclusions and Policy Implications}

[51] Users of common pool resources can develop exploitation plans based on various cooperative management institutions. Comparison of the results of this study with previous studies, using noncooperative and exogenously imposed regulations suggests that cooperative management institutions are the most efficient methods in prolonging the CPR's life and increasing the long-term benefits to its users. However, adopting these institutions in practice may be more challenging than the other two categories of institutions, due to their rigorous mathematical nature as well as

Table 9. Power Indices of the Farmers Under Different Cooperative Management Institutions Based on Their Choice of Management Institution in the Status Quo

\begin{tabular}{|c|c|c|c|c|c|c|}
\hline \multirow[b]{2}{*}{$\begin{array}{l}\text { Cooperative } \\
\text { Management } \\
\text { Institution }\end{array}$} & \multicolumn{6}{|c|}{ Noncooperative Management Institution } \\
\hline & $\begin{array}{c}\text { Ignorant Myopic } \\
\text { Management }\end{array}$ & $\begin{array}{c}\text { Smart Myopic } \\
\text { Management With } \\
\text { Drawdown Penalty }\end{array}$ & $\begin{array}{c}\text { Smart Myopic } \\
\text { Management With } \\
\text { Profit Penalty }\end{array}$ & $\begin{array}{l}\text { Fixed Ignorant } \\
\text { Nonmyopic } \\
\text { Management }\end{array}$ & $\begin{array}{c}\text { Variable Ignorant } \\
\text { Nonmyopic } \\
\text { Management }\end{array}$ & $\begin{array}{c}\text { Smart Nonmyopic } \\
\text { Management }\end{array}$ \\
\hline \multicolumn{7}{|l|}{ Nash-Harsanyi } \\
\hline Farmer A & 0.38 & 0.37 & 0.37 & 0.33 & 0.33 & 0.33 \\
\hline Farmer B & 0.38 & 0.37 & 0.37 & 0.33 & 0.33 & 0.33 \\
\hline Farmer C & 0.25 & 0.26 & 0.26 & 0.33 & 0.33 & 0.33 \\
\hline \multicolumn{7}{|l|}{ Shapley } \\
\hline Farmer A & 0.37 & 0.38 & 0.35 & 0.33 & 0.32 & 0.29 \\
\hline Farmer B & 0.39 & 0.39 & 0.41 & 0.40 & 0.41 & 0.44 \\
\hline Farmer C & 0.24 & 0.24 & 0.24 & 0.27 & 0.27 & 0.26 \\
\hline \multicolumn{7}{|l|}{ Nucleolus } \\
\hline Farmer A & 0.41 & 0.42 & 0.37 & 0.31 & 0.31 & 0.26 \\
\hline Farmer B & 0.44 & 0.44 & 0.49 & 0.48 & 0.48 & 0.48 \\
\hline Farmer C & 0.15 & 0.14 & 0.14 & 0.21 & 0.21 & 0.26 \\
\hline
\end{tabular}




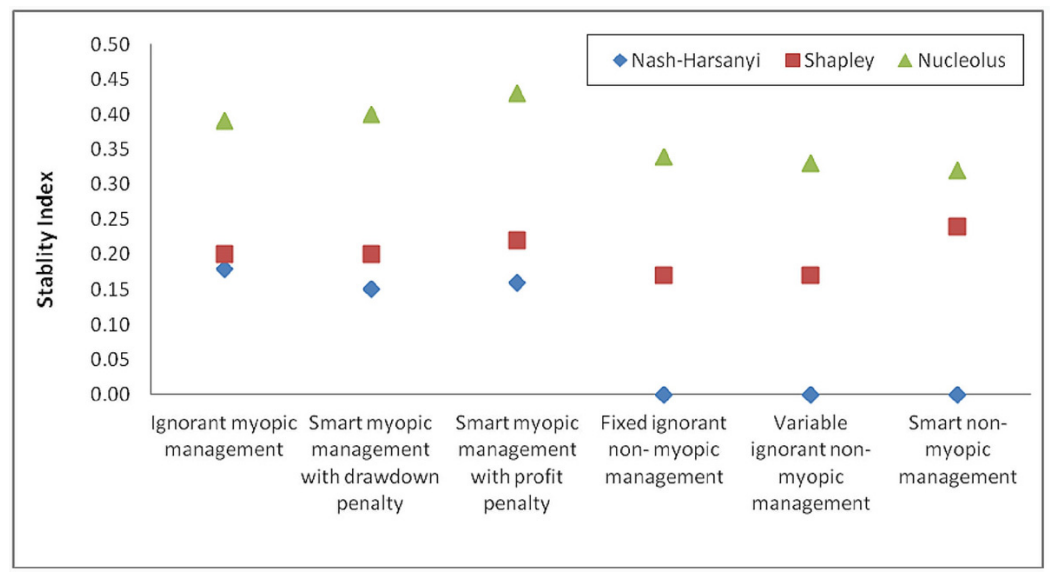

Figure 2. Stability indices under different cooperative management institutions based on farmers' choice of management institution in the status quo.

lack of trust among the users, limited information and knowledge, presence of many users, etc. While implementation of cooperative institutions may be challenging in practice, governments can help enforce these institutions by creating different incentives for cooperation (e.g., tax write-off, development loans, monitoring mechanisms, and technical advice).

[52] The maximum obtainable benefit by the CPR users can be calculated using a social plannner solution. Yet, this approach cannot suggest stable and acceptable cooperative solutions because it ignores what each individual will incrementally gain under cooperation. Therefore, cooperative game theory allocation solutions such as the core, NashHarsanyi, Shapley, and nucleolus can be applied to determine efficient and fair allocation solutions that are acceptable by the users. These methods consider the contribution of each CPR beneficiary to the grand coalition, and their gains in case of noncooperation and suggest solutions that minimize the users' incentives to leave the grand coalition to act on their own or form subcoalitions with other users.

[53] As indicated using the numerical example, application of the plurality rule or measurement of stability through calculation of the propensity to disrupt, power index, and stability index may not necessary lead to an accurate prediction of the most stable and likely outcome. Nonetheless, these methods are helpful in finding the highly unstable outcomes. To better suggest a stable outcome, one should consider the conditions of the problem, and various factors that may affect the stability of a solution in practice (e.g., powers of the parties in allocating more resources to them), and transactions costs.

[54] It is also important to note that the final cooperative solution does not always match the values suggested by the introduced cooperative management institutions. However, with the knowledge of propensity to disrupt values and power indices, and more information about the problem's conditions in practice, it is possible to develop a stable solution by tweaking the solutions suggested by the cooperative management institutions. In fact, these institutions can suggest solutions that are close to what will eventually be found stable and fair by the parties in practice. Therefore, they are helpful in suggesting suboptimal solutions for initiating the bargaining process over the gains out of cooperation.

[55] Results of the study show that as users become less myopic and less ignorant, they benefit less from cooperation with respect to what they gain under noncooperation. Also, the ranges of acceptable solutions by the users get more limited as they become more considerate of the externalities and long-term benefits from the CPR, resulting in a smaller core. Thus, the acceptable cooperative solutions are more limited for nonmyopic smart users and result in higher propensities to disrupt for these users. While potentially this results in hardship in enforcing cooperative solutions among this type of users, due to a better knowledge about the externalities and long-term benefits, theoretically, developing practical cooperative solutions among these users should be easier than for myopic ignorant users who are more focused on immediate benefits from the resource. Nevertheless, when transaction costs of enforcing cooperation are high, regulators may seek a sustainable use of the CPR through educating the users to replace their myopic ignorant behavior with nonmyopic smart behavior.

\section{Appendix A: Extreme Points of the Core}

[56] As an example, the core equations for cooperation of farmers who use variable ignorant nonmyopic management under noncooperation can be written as follows:

$$
\begin{gathered}
u_{A}^{*} \geq 2,209,329 \\
u_{B}^{*} \geq 744,047 \\
u_{C}^{*} \geq 40,259 \\
u_{A}^{*}+u_{B}^{*} \geq 3,763,309 \\
u_{A}^{*}+u_{C}^{*} \geq 2,682,139 \\
u_{B}^{*}+u_{C}^{*} \geq 1,459,786 \\
u_{A}^{*}+u_{B}^{*}+u_{C}^{*}=4,394,518
\end{gathered}
$$


Table A1. Extreme Points of the Core for the Farmers Who Use Variable Ignorant Nonmyopic Management Under Noncooperation

Maximum Incremental Benefit Allocation of Farmer $i, i=\mathrm{A}, \mathrm{B}, \mathrm{C}$

\begin{tabular}{cccc}
\hline $\mathrm{A}$ & $\mathrm{B}$ & $\mathrm{C}$ & $\begin{array}{c}\text { Grand Coalition } \\
\text { Formation Sequence }\end{array}$ \\
\hline $2,209,329$ & $1,553,980$ & 631,209 & $\mathrm{ABC}$ \\
$2,209,329$ & $1,712,378$ & 472,810 & ACB \\
$3,019,262$ & 744,047 & 631,209 & BAC \\
$2,934,732$ & 744,047 & 715,739 & BCA \\
$2,641,880$ & $1,712,378$ & 40,259 & CAB \\
$2,934,732$ & $1,419,527$ & 40,259 & CBA \\
\hline
\end{tabular}

[57] The above set of inequalities suggests a range of solutions that may be acceptable by the three farmers in case of cooperation when each uses the variable ignorant nonmyopic management under noncooperation. Based on these equations, it is possible to calculate the extreme points of the core [Shapley, 1971] to find the ordering of the farmers' preferences over the possible cooperative solutions [Dinar and Howitt, 1997]. To do so, we should consider all the possible sequences for formation of the grand coalition. Table A1 shows such sequences together with the extreme points of the core for the farmers who use variable ignorant nonmyopic management under noncooperation, based on the values of Tables 4 and 5 .

[58] The extreme points of the core and the incremental benefit allocation of the farmers, adopting the variable ignorant nonmyopic management institution, are calculated as follows: As an example for the grand coalition sequence $\mathrm{ABC}$, it is assumed that first farmer $\mathrm{A}$ joins the empty coalition with a zero value and creates coalition $\{\mathrm{A}\}$ with associated value of $\$ 2,209,329$. Then farmer $B$ joins the coalition and creates coalition $\{\mathrm{A}, \mathrm{B}\}$ with the value of $\$ 3,763,309$ (given in Table 5). Therefore, the contribution of farmer B to the new coalition is $\$ 3,763,309-\$ 2,209,329=\$ 1,553,980$, which is the maximum benefit he can expect to obtain from cooperating with farmer $\mathrm{A}$. By joining farmer $\mathrm{C}$ to this coalition, the grand coalition $\{\mathrm{A}, \mathrm{B}, \mathrm{C}\}$ is created with total worth of $\$ 4,394,518$. The contribution of farmer $\mathrm{C}$ to the grand coalition with the $\mathrm{ABC}$ sequence is $\$ 4,394,518$ - \$3,763,309 $=\$ 631,209$, which is the maximum he can expect from participating in the grand coalition, when he is the last one to join. The values, given in Table A1, show the incremental contributions of the farmers to different sequential formations of the grand coalition. In fact, these numbers indicate the minimum and maximum expected benefit allocation of the farmers, or the farmers' preference orders over the possible allocation. For instance, farmer A prefers allocations under which he can gain a profit close to $\$ 3,019,262$ (the highest number in farmer A's column in Table A1) to allocations under which his gain is close to \$2,209,329 (the lowest number in farmer A's column in Table A1). This farmer does not accept any allocation scheme that provides him less than $\$ 2,209,329$.

[59] Acknowledgments. The first author thanks the Water Science and Policy Center (WSPC) at University of CA, Riverside and the Center for Watershed Sciences at University of CA, Davis for funding this research during his postdoctoral research at WSPC. The authors thank Carmen Marchiori at the London School of Economics and Political Science and the anonymous reviewer for their valuable constructive comments.

\section{References}

Blomquist, W. A. (1992), Dividing the Waters : Governing Groundwater in Southern California, 415 pp., ICS Press, San Francisco, Calif.

Brams, S. J., and D. M. Kilgour (2001), Fallback bargaining, Group Decis. Negotiation, 10(4), 287-316.

Burke, J. J., C. Sauveplane, and M. Moench (1999), Groundwater management and socio-economic responses, Nat. Resour. Forum, 23, 303313.

Castillo, D., and A. K. Saysel (2005), Simulation of common pool resource field experiments: A behavioral model of collective action, Ecol. Econ., 55(3), 420-436.

Cazorla, M., and M. Toman (2000), International equity and climate change policy, report, 20 pp., Resour. for the Future, Washington, D. C.

Chebaane, M., H. El-Naser, J. Fitch, A. Hijazi, and A. Jabbarin (2004), Participatory groundwater management in Jordan: Development and analysis of options, Hydrogeol. J., 12(1), 14-32.

Davis, M., and M. Maschler (1965), The kernel of a cooperative game, Nav. Res. Logistics Q., 12, 223-259.

Dinar, A. (2001), Scale and equity in water resources development: A Nash bargaining model, Nat. Resour. Model., 14(4), 477-494.

Dinar, A., and R. E. Howitt (1997), Mechanisms for allocation of environmental control cost: Empirical Tests of acceptability and stability, $J$ Environ. Manage., 49, 183-203.

Dinar, A., D. Yaron, and Y. Kannai (1986), Sharing regional cooperative gains from reusing effluent for irrigation, Water Resour. Res., 22(3), 339-344.

Dinar, A., A. Ratner, and D. Yaron (1992), Evaluating cooperative game theory in water resources, Theory Decis., 32(1), 1-20.

Faysse, N. (2005), Coping with the tragedy of the commons: Game structure and design of rules, J. Econ. Surv., 19(2), 239-261.

Fehr, E., and U. Fischbacher (2002), Why social preferences matter-The impact of non-selfish motives on competition, cooperation and incentives, Econ. J., 112(478), C1-C33.

Gardner, R., E. Ostrom, and J. M. Walker (1990), The nature of commonpool resource problems, Rationality Soc., 2(3), 335-358.

Gardner, R., M. R. Moore, and J. M. Walker (1997), Governing a groundwater commons: A strategic and laboratory analysis of western water law, Econ. Inquiry, 35(2), 218-234.

Gately, D. (1974), Sharing the gains from regional cooperation: A game theoretic application to planning investment in electric power, Int. Econ. Rev., 15(1), 195-208.

Gillies, D. B. (1959), Solutions to general non-zero-sum games, in Contributions to the Theory of Games, edited by A. W. Tucker and R. D. Luce, pp. 47-85, Princeton Univ. Press, Princeton, NJ.

Gisser, M. S. D. (1980), Competition versus optimal control in groundwater pumping, Water Resour. Res., 16, 638-642.

Gordon, H. S. (1954), The economic-theory of a common-property resource: The fishery, J. Political Econ., 62, 124-142.

Hardin, G. (1968), The tragedy of the commons, Science, 162(3859), 12431248.

Harsanyi, J. C. (1959), A bargaining model for the cooperative n-person game, in Contributions to the Theory of Games, edited by A. W. Tucker and D. R. Luce, pp. 324-356, Princeton Univ. Press, Princeton, N. J.

Harsanyi, J. C. (1963), A simplified bargaining model for the n-person game, Int. Econ. Rev., 4, 194-220.

Kilgour, D. M., N. Okada, and A. Nishikori (1988), Load control regulation of water pollution: An analysis using game theory, J. Environ. Manage., 27(2), 179-194.

Konikow, L. F., and E. Kendy (2005), Groundwater depletion: A global problem, Hydrogeol. J., 13, 317-320.

Koundouri, P. (2004), Current issues in the economics of groundwater resource management, J. Econ. Surv., 18, 703-740.

Lejano, R., and C. Davos (1995), Cost allocation of multiagency water resource projects: Game theoretic approaches and case study, Water Resour. Res., 31(5), 1387-1393.

Lejano, R. P., and C. A. Davos (1999), Cooperative solutions for sustainable resource management, Environ. Manage., 24(2), 167-175.

Lindroos, M., and V. Kaitala (2000), Nash equilibria in a coalition game of the Norwegian spring-spawning herring fishery, Mar. Resour. Econ., 15(4), 321-339.

Loaiciga, H. A. (2004), Analytic game-theoretic approach to ground-water extraction, J. Hydrol., 297(1-4), 22-33.

Loehman, E. (1995), Cooperative solutions for problems of water supply, in Water Quantity/Quality Management and Conflict Resolution: Institutions, Processes, and Economic Analyses, edited by A. Dinar and E. Loheman, pp. 301-319, Praeger, Westport, Conn. 
Loehman, E., and A. Whinston (1976), A generalized cost allocation scheme, in Theory and Measurement of Economic Externalities, edited by A. Stevens and Y. Lin, pp. 87-110, Academic, Orlando, Fla.

Loehman, E., J. Orlando, J. Tschirhart, and A. Winstion (1979), Cost allocation for a regional wastewater treatment system, Water Resour. Res., $15,193-202$.

Madani, K. (2010), Game theory and water resources, J. Hydrol., 381(3-4), 225-238.

Madani, K. (2011), Hydropower licensing and climate change: Insights from cooperative game theory, Adv. Water Resour., 34(2), 174-183.

Madani, K., and A. Dinar (2011), Exogenous regulatory institutions for sustainable management of common pool resources report, Working Pap. 01-0311, Water Sci. and Policy Cent., Univ. of Calif., Riverside.

Madani, K., and A. Dinar (2012), Non-cooperative institutions for sustainable management of common pool resources, Ecol. Econ., 74, 34-45.

Madani, K., and K. W. Hipel (2011), Non-cooperative stability definitions for strategic analysis of generic water resources conflicts, Water Resour. Manage., 25(8), 1949-1977.

Madani, K., and J. R. Lund (2011), A Monte-Carlo game theoretic approach for multi-criteria decision making under uncertainty, $A d v$. Water Resour., 34(5), 607-616.

Munro, G. R. (2009), Game theory and the development of a resource management policy: The case of international fisheries, in Game Theory and Policy Making in Natural Resources and the Environment, edited by A. Dinar, J. Albiac, and J. Sánchez-Soriano, pp. 7-27, Routledge, London.

Nash, J. (1951), Non-cooperative games, Ann. Math., 54(2), 286-295.

Nash, J. (1953), Two-person cooperative games, Econometrica, 21(1), $128-140$.

Negri, D. (1989), The common property aquifer as a differential game, Water Resour. Res., 25(1), 9-15.

Okada, N., and Y. Mikami (1992), A game-theoretic approach to acid rain abatement: Conflict analysis of environmental load allocation, Water Resour. Bull., 28(1), 155-162.

Ostrom, E. (1990), Governing the Commons: The Evolution of Institutions for Collective Action, 280 pp., Cambridge Univ. Press, Cambridge, U. K.

Ostrom, E. (1998), A behavioral approach to the rational choice theory of collective action, Am. Political Sci. Rev., 92(1), 1-22.

Ostrom, E. (2010), Beyond markets and states: Polycentric governance of complex economic systems, Am. Econ. Rev., 100(3), 641-672.

Ostrom, E., R. Gardner, and J. Walker (1994), Rules, Games, and CommonPool Resources, 369 pp., Univ. of Mich. Press, Ann Arbor.

Parrachino, I., A. Dinar, and F. Patrone (2006), Cooperative game theory and its application to natural, environmental, and water resource issues: 3. Application to Water Resources, World Bank Policy Research Working Paper 4074, WPS4072, World Bank, Washington, D. C.

Petrosjan, L., and G. Zaccour (2003), Time-consistent Shapley value allocation of pollution cost reduction, J. Econ. Dyn. Control, 27(3), 381-398.

Provencher, B., and O. Burt (1993), The externalities associated with the common property exploitation of groundwater, J. Environ. Econ. Manage., 24(2), 139-158.

Ross, A., and P. Martinez-Santos (2009), The challenge of groundwater governance: Case studies from Spain and Australia, Reg. Environ. Change, 10(4), 299-310.

Sandler, T. (1992), After the cold war, secure the global commons, Challenge, 35(4), 16-23.
Schmeidler, D. (1969), The nucleolus of a characteristic function game, SIAMJ. Appl. Math., 17, 1163-1170.

Selbirak, T. (1994), Some concepts of non-myopic equilibria in games with finite strategy sets and their properties, Ann. Oper. Res., 51(2), 73-82.

Shah, T., D. Molden, R. Sakthivadivel, and D. Seckler (2000), The global groundwater situation: Overview of opportunities and challenges, report, Int. Water Manage. Inst., Colombo, Sri Lanka.

Shah, T., M. Giordano, and J. Wang (2004), Irrigation institutions in a dynamic economy: What is China doing differently from India?, Econ. Political Weekly, 39, 31 July, 3452-3461.

Shapley, L. S. (1953), A value for n-person games, Ann. Math. Stud., 28, 307-318.

Shapley, L. S. (1971), Cores of convex games, Int. J. Game Theory, 1, $11-26$.

Shapley, L. S., and M. Shubik (1954), A method for evaluating the distribution of power in a committee system, Am. Political Sci. Rev., 48, 787 792.

Sheikhmohammady, M., and K. Madani (2008), Bargaining over the Caspian Sea-The largest lake on the Earth, paper presented at World Environmental and Water Resources Congress 2008: Ahupua'a, Am. Soc. of Civ. Eng., Honolulu, Hawaii.

Straffin, P. D., and J. P. Heaney (1981), Game theory and the Tennessee Valley Authority, Int. J. Game Theory, 10, 35-43.

Suzuki, M., and M. Nakayama (1976), The cost assignment of the cooperative water resource development: A game theoretical approach, Manage. Sci., 22(10), 1081-1086.

Taylor, M. (1987), The Possibility of Cooperation, Cambridge Univ. Press, Cambridge, U. K.

Theis, C. V. (1935), The relation between the lowering of the piezometric surface and the rate and duration of discharge of a well using ground water storage, Eos Trans. AGU, 16, 519-524.

Tijs, S. H. (1981), Bounds for the core of a game and the $\tau$-value, in Game Theory and Mathematical Economics, edited by O. Moeschlin and D. Pallaschke, pp. 123-132, North-Holland, Amsterdam.

Villholth, K. G. (2006), Groundwater assessment and management: Implications and opportunities of globalization, Hydrogeol. J., 14, 330-339.

Wegerich, K. (2006), Groundwater institutions and management problems in the developing world, in Urban Groundwater Management and Sustainability, vol. 74, sect. viii, pp. 447-458, edited by J. H. Tellam et al., Springer, Dordrecht, Netherlands.

World Water Assessment Programme (2003), Water for people, water for life, report, U. N. Educ., Sci. and Cultural Organ., Paris.

Worthington, V. E., O. R. Burt, and R. L. Brustkern (1985), Optimal management of a confined groundwater system, J. Environ. Econ. Manage., 12(3), 229-245.

Young, H. P., N. Okada, and T. Hashimoto (1982), Cost allocation in water resources development, Water Resour. Res., 18(3), 463-475.

Zara, S., A. Dinar, and F. Patrone (2006), Cooperative game theory and its application to natural, environmental, and water resource issues: 2 . Application to natural and environmental resources, World Bank Policy Research Working Paper 4073, WPS4072, World Bank, Washington, D. C.

Zilberman, D., A. Dinar, N. MacDougall, M. Khanna, C. Brown, and F. Castillo (1998), Private and institutional adaptation to water scarcity during the California drought, 1987-1992, report, U.S. Dep. of Agric., Washington, D. C. 